\title{
Communication as a Component of the Quality of Life in the Integrated Care for the Dying
}

\author{
Mateja Berčan, RN, spec, MSN
}

Alma Mater Europaea - European Centre Maribor, Slovenia; mateja.bercan@siol.net

Prof. ddr. Marija Ovsenik

Alma Mater Europaea - European Centre Maribor, Slovenia

Doi:10.5901/mjss.2016.v7n3s1p70

\begin{abstract}
In Slovenia, a half of all people still die at hospital or care institutions. Therefore, our intention was to find out about communication as one of the basic component of life quality in the process of palliative care. The aim of the research was to determine how communication skills and knowledge of 181 community nurses, members of the primary and specialist palliative team, affect implementation of the integrated care of the dying at home. The data collected by an interview questionnaire were analyzed by relevant quantitative statistical methods. It was found out that communication and knowledge statistically significantly effect knowledge about disease and palliative care plan of patients and their families. Communication builds trust and is foundation for overcoming obstacles in providing quality care for the dying.
\end{abstract}

Keywords: palliative care, community nursing care, domestic environment, team work

\section{Introduction}

Great puzzle of human life is not suffering, but death (Weil, 1985, p.78). Puzzle is also a disease that brings suffering, which paralyzes life and converts it into an image of death. The role and function of integrated care is therefore directed to mitigate this process.

Growing elderly population and increasing number of chronic diseases, consequently increases the need for palliative care. In Slovenia, more than 50 percent of people still die in health care facilities (Statistical Office of the Republic of Slovenia, 2012). Authors (Burge, Lawson \& Johnston, 2003; Higginson, Astin \& Dolan, 1998) note that in the future the share of the people dying at home environment will have to increase. Consequently, it will be necessary to intensify palliative care the home. A leader in the field of palliative care in Europe - Great Britain - in the last six years has for the first time, since 1974, when the proportion of dying in hospitals was in steady increase, achieved tendency of increase of the proportion dying at their homes (Gomes, Calanzani \& Higginson, 2012).

In order to enable patients to stay at home even during the progression of incurable diseases, and especially at the time of death, it is necessary to ensure the continuity of primary health care, community nursing, social work, occupational therapy, physiotherapy, dietetics and pharmacy. It is palliative care, which offers care to patients and support families and also informal care providers. Palliative care provides optimal physical, psychological, spiritual and social support to the patient and his family at all stages of dying. Target orientation of palliative care is therefore focused on providing high-quality of the dying in domestic environment. In Slovenia, model of integrated care of the dying in the domestic environment has not been implemented yet. Dealing with this problem, we are again and again encountered with a communication problem. So, our intention was to carry out a research on communication between members of the palliative team and knowledge of how to offer quality care to palliative patients, according to community nurses, and how it statistically significant effects patient and family's familiarity with the course of a disease and palliative care plan.

\section{Theoretical Standpoints}

We are looking for the reason why the death disappeared from public life; why it has become a taboo subject and is being moved to institutions. Awareness of the fact that each of us prefers dying where we feel safe - at home, has lost its weight. But we know that an individual, as well as their closest, deal with death easiest if they experience it together, in interaction, in the domestic environment.

But the adoption of dying is a long way, although limited in time. Therefore, palliative care is not just an idea; it is a 
need, an urgent reality. There is no consent of the professionals regarding this issue. It is stated that the implementation of palliative care at the patient's home in Slovenia, in compliance with regulations, is based on the palliative team. The team includes health care and nursing providers, medical staff and other professionals, non-professional trained providers - volunteers and patient's relatives (Ministry of Health of the Republic of Slovenia, 2010). A patient and their close relatives participate as equal members of the team. Their attention is focussed to relevant and unique things from the patient's perspective and preserving their normal way of self-care, helping them maintain a sense of self (Corner, 2003).

There is almost nothing written or defined about communication in this team, but communication is a central driving force of the relationship between the teams, and dying relatives, which establishes quality co-operation, or, reduces it to only impersonal urgent chores, not allowing development of the quality relationship.

Hospitals intended for the treatment are becoming the place of dying. This transformed role has brought a spectrum of problems. Most doctors prescribe treatments to prolong life, even though they know that a man is dying. Fear and incompetence in matters of dying implies fear of possible criticism. Even the family is looking for an excuse for perhaps not entirely appropriate care for the dying, before dying, asking for new therapies to be applied. Our tendency to overcome this prejudice is certainly a sign that we are impregnated with it. The patient, who is dying, becomes/is a reminder of the failure of medical approaches. The dying becomes unnecessary foreign body, consequently feeling impersonal and alienated in hospitals and nursing/care homes. The dying just cannot be helped. More than services, they need closeness. Relationship/attitude. The relationship is at the heart of communication, especially with the dying.

\section{Reasons for Dying at Home}

Klevišar (1996) presents three reasons why so few people die at home nowadays:

- most often cause lies in the lack of experience related to dying, causing fear of dying;

- too high expectations of health professionals regarding the appropriate functioning of the family;

- families actually do not have possibility to monitor the dying at home, because they are at work or at schools. The reason may also be physical and financial barriers.

Idyllic seems to be a look back, when the children had the opportunity to accompany the dying next to their bed. They were present at the time of their death. They experienced a death as a part of life, understood it as an important signal/mile stone. Today, people have no contact with the death until their late age, and they fear and try to run away/escape dying. They are not aware that medicine remains without power when dealing with progressive, incurable diseases. Delegating care of the family into the hands of experienced professionals is one of the obvious symptoms that indicate death as a taboo and only increases fear of it.

Modern science is more and more prone to emphases development of palliative care in the domestic environment. Not only because the patient can stay at home and active role in care is taken over by families, but mainly because the emotional connection is being thorn spontaneously, because home is a space where we have time for genuine communication which the dying need. During the treatment of the patient and active involvement of relatives in the care, enable loved ones and the patient to prepare them for the final farewell and avoid the feeling of helplessness. Therefore, the main focus of the implementation of palliative care is to enable dying and death at home, among their loved ones. Relief of accompanying symptoms is not limited to physical symptoms, psychosocial and spiritual distress and problems have to be relieved, too (Peternel, 2008). When its desires were robbed, when its secrets were robbed, body sensitivity itself becomes something general. (Weil, 1985, p. 59).

\section{Social Environment}

The population in developed countries is aging rapidly. Slovenia is also at the top of statistical tables of demographic aging. Long-term population projections, prepared by the Eurostat for the EU Member States, on the basis of a uniform methodology for the period till 2050, indicate a further increase of the elderly in Slovenia. Their forecast says that the proportion of the elderly population 64+ will be significantly increased; especially the population aged over 80 years.

In the recent decades, in the countries of Western Europe, organized palliative care has expanded enormously, both, within and outside the health care system, mainly due to the accelerated aging of the population and increase in the proportion of patients with severe chronic diseases and cancer, which will, according to the projected demographic statistics, escalate in the future (Murayama \& Lopez, 1997). Palliative care, as defined by the World Health Organization (WHO), should be part of public health care, and accessible to all. Or otherwise - an access to palliative care is a human right under the United Nations Convention (WHO, 2004). 
Access to care should be based on patients' needs and preferences, regardless of the place of residence, financial status, type of disease, age, sex or any other criterion. If the aim of palliative care is quality of life for patients with advanced incurable chronic disease, we must be aware that the disease has, along with human experience, far exceeded the boundaries of the field of medicine. Quality of life reached the socio-gerontological field, where relationship and communication are in the centre and the key forces of the quality of human life in palliative care.

\subsection{Relatives in the Process of Palliative Care}

Change of generations changes attitudes to death. In the past, people used to be more familiar with death. Even children were faced with dying relative's death in the neighbourhood. They were confronted with the customs and rituals related to death, so that the fact of death was socialized. Families were larger in number, more generations used to live together. Thus, the dying and the grieving were experienced together. Monitoring of the dying is one of the hardest things in life and marks us, although we are enriched (Klevišar, 1997). Advanced chronic incurable disease that leads to death, destroys family balance. It changes relations between family members, family roles are replaced, the patterns of decisionmaking and behaviour can be compromised, so as the development of certain family members (Slak, 2011). The outside world (health workers and associates) penetrates into the intimacy of the family life. All these factors can cause insecurity, anxiety, overload and severe distress in the family with a dying patient. For this reason, it is important to listen to the needs of relatives, to provide them with emotional support and help them adapt to change. It is necessary to encourage an informed openness in the relationship, because communication during the last days of life impact over bridging barriers from the past and facilitates the recognition that there are no unsolved hardships from the past. This prevents the development of any mental or physical symptoms. Open and calm communication with relatives is essential. The World Health Organization argues that the inclusion of palliative care improves the quality of life not only for patients but also for their relatives.

Studies found out that palliative care enables significantly better quality of life of patients and their family members. It has a very strong impact on their mutual relations (Qaseem, Snow, Shekelle, Casey, Cross \& Owens, 2008; Brumley, Enguidanos, Jamison, Seitz, Morgenstern, Saito, Mcllwane, Hillary \& Gonzales, 2007; El-Jawahri, Greer \& Temel, 2011). Various studies tried to find answers to questions of how the experience of long-term illness interferes with partnership. In one study (Keller, Heinrich, Sellschopp \& Beutel, 1996) patients reported that the partnership improved during and after the disease, which is inconsistent with the survey (Joly, Heron, Kalusinski, Henry - Amar \& Allouache, 2002), where the authors argue that the advanced malignant disease escalated conflict in relationships and lack of understanding of the patient's partner. Certainly, single answer has not been found yet.

\subsection{Greiving}

Grief is an emotion that responds to the loss of an individual. The most common loss which triggers grief is the death of a loved one. It is an emotional response to the loss, losing its intensity with the time. "It is a time-consuming and multilayered process, in which the grieving processes their loss, and adjusts to the loss. It contains behavioural, emotional, social, physical and spiritual components "(Tekavčič-Grad in Marusic \& Roškar, 2003). In the literature there are different understandings of grief, some consider it as the period after the loss, the others as an experience of loosing somebody. It does not matter whether a man was taken away by life or death - the consequences are the same: emptiness, sadness, despair (Ovsenik, 2014).

In Slovenia, palliative care does not provide support for families and caregivers in the period of mourning process. After the death of a patient, family members or primary caregivers are left to relatives, neighbours and to themselves. We still do not provide formal support to families after the death of the patient in the domestic environment. Even the payer of the services - Health Insurance Institute of Slovenia - does not cover costs for the visit of the primary caregiver or family of the deceased. Field, Reid, Payne \& Relf (2006) note that nurses are the ones who are most involved in supporting families in the process of mourning, but (Chang, Bidewell, Hancock, Johnson \& Esterbrook, 2012), they are only rarely trained in this field. This can also be stated for Slovenia, where we can highlight the lack of personnel, funding problems, and ignorance.

\subsection{Professional Staff}

Our performance is reflected in our actions. Giddens points out that the performance is not always conscious and deliberate, as many actions arise from sub consciousness, habits and the like. However, large part of the performance is 
a result of thought, which means that individuals, in our case professionals, usually control consequences of their actions in contact with the dying patients, and responses to the environment, and according to this acting, they are even more efficient. In this respect, we are talking about »the intention/aim« and it is knowledgeability, which defines any action that a performer takes along a path of a higher quality of performance (Giddens 1989). Regarding Giddens, individuals in the course of their daily practices continuously monitor consequences of actions and correct them promptly, but at the same time, a set of consequences are generated which actors had not predicted (Giddens, 1984), what means that the effects became a frame of new actions. This concept in Gidden's theory is very important, because it shows how individual action might lead to some structural changes, which go far beyond the original intent, and that in the course of everyday events are shown as something "external", as something they cannot effect/have no influence on. Practitioners are still clinging to the notion that life should be extended at any cost, even with the help of aggressive practices and health-care interventions, which only prolong the pain and suffering of the dying. Death and dying are perceived as a failure of medical science and our own helplessness, therefore, they are extremely reluctant to speak about these issues.

\subsection{Integrated Approach in the Process of Palliative Care}

Integrated care is a well-planned and well-organized set of services and processes of care, directed to the multidimensional needs and problems of individuals, or to the category of people with similar needs or problems (Nies \& Berman, 2004). Integrated care is trying to meet the long-term, complex and multiple needs of patients in the process of palliative care, and offers them the opportunity to live their lives as they want. Wishes and needs must be arranged in the interaction between professionals, patients and relatives. This interaction is at the heart of care.

Recently, concept of "integrated approach" is becoming very common (Gholve, Kosygan, Sturdee \& Faraj, 2005; Arnaert, Van Den Heuvel \& Windey, 2005; Volkers, Nuyen, Verhaak \& Schellevis, 2004; Schwenk, 2002; 158; Landi, Onder, Russo, Tabaccanti, Rollo, Federici, Tua, Cesari \& Bernabei, 2001). Integration is understood as reciprocity between actors and collectivities in dealing with health and disease, and its ultimate goal is quality of life. Giddens, in his theory of structuring, deals with social and system integration. Social integration is based on the actors and their relations in the context of co-presence. He implicitly talks about communication, throughout all five channels of communication: verbal, visual, olfactory, kinesthetic and gustatory. This concept can also be used in the treatment of the patient in the process of palliative care. In the process of palliative care, an integrated approach is the one which enables a patient, his family and friends to equally cooperate with the professionals of various disciplines, as palliative care is seen as the integration of mental, physical, social and spiritual care, in the context of interaction in time and space. Central point in »the concept of nursing in palliative care becomes quality of life - both, of the patient as well as families.

\subsection{Team Approach in the Process of Palliative Care}

The concept of team work in palliative care, based on the pioneering work of Cicely Sounders, included multi-dimensional needs of patients and comprehensive multidisciplinary team approach (Gomez-Batiste, Martinez-Munoz, Blay, Espinosa, Contel \& Ledesma, 2012).

Thinking about physical, emotional and social challenges when living with the disease, gets a completely different dimension in patients who are faced with the progression of the disease and approaching death.

In the interdisciplinary team, experts identify themselves with an identity of a team. The team members, depending on the current task, take the lead in the team. In order to achieve the objectives, pieces of information are distributed among team members and co-ordinated work is carried out competently.

The interdisciplinary team cooperates, which is vital for its success. Negotiation and debate are fundamental elements of the interdisciplinary team; each member of the team is ready to take into account the views of other members (Ovsenik \& Ambrož, 2010).

Despite the theoretical differences between multidisciplinary and interdisciplinary teams, their functioning over lapses. Regarding patient's needs, negotiation and discussion become essential approach in providing high-quality palliative care. Only with the empathic sharing of information about the patient's condition and the corresponding care, interdisciplinary team can provide holistic palliative care to a patient in a terminal stage. Or, according to Giddens - it is the ability of actors to explain to themselves as well as to others, the reasons for a particular direction of action, which the author calls "discursive consciousness" (1984). It means that actors justify the reasons for their actions, suggesting a fundamental feature of the operation, which can not be only a passive role played within certain structural relationships. 


\subsection{Communication}

Communication has one of the most important roles in palliative care. Patients and their family members state that communication is one of the most important skills of all involved in the process of palliative care (Shanawani, Wenrich, Tonelli \& Curtis, 2008). Experts note that practitioners are obliged to talk in time and on emotionally-intelligent way to patients about their health, psychosocial and spiritual needs at the end of their lives (Quill, 2000). Although, this is a strong emotional and intellectual effort, patients and their family members want to be informed. Systematic scientific review of 46 studies demonstrated that patients with chronic incurable disease have a high level of demand for complex information in all phases of their disease (Parker, Clayton, Hancock, Walder, Butow, Carrick, Currow, Ghersi, Glare, Hagerty \& Tattersall, 2007). Patients ask questions about the end of life, namely:

- about the process of disease:

- about prognosis for survival and quality of life;

- about projected symptoms and their management;

- about the methods of treatment and how it will affect the length and quality of life;

- about nursing care plan.

Researches have also shown a very low rate of effective communication skills among professionals, especially in terms of communicating "bad news" (Reinke, Slatore, Uman, Udris, Moss, Engelberg \& Au David, 2011; Buckman, 1984). Bad news is any news about the patient's state of health, which a doctor or a nurse communicate to a patient or his loved ones, and can have, due to the content or the conditions in which it is transmitted, a negative impact on the recipient due to the nature of the medical condition, or the impact this condition has on the patient's ability to operate on the physical, mental, social, family and existential field (Lunder \& Kersnik, 2003). Psychologist, Cathy Heaven (1996) throughout her researches on communication between health professionals and patients, found out that the health professionals most often used strategies to avoid patient's problems. (Wilkinson, 1991).

\subsection{Education}

In the strategy of the care of the dying, (Department of Health, 2008) there is a special chapter devoted to education. Health and social workers, who have completed formal education, must constantly renew and upgrade their knowledge. This education should also cover a special area of knowledge - knowledge of communication. Assertiveness, which is hard to detect at professional workers, is one of the issues which should be pointed out. Authors of the strategy found that many doctors, nurses and other key experts, have neither professional nor communication competences in providing high-quality care for the dying. In recent years, a model for improvement of the communication skills of the health professionals who had not gained these skills in their formal education, has been developed. This model includes a threeday course that is entirely focused on the "participant". It is based on the problems and challenges at work, which the participant recognizes as important and would like to learn about them more. Or, according to Giddens - individuals are because of their knowledge, skills and reflexivity capable of creating always new solutions, which often, if not pull down, but at least change the original structural relationship (Giddens, 1984).

\subsection{Community Nursing in the Process of Palliative Care}

In prehistoric times, a sick man was nurtured by his mother, wife or other relative, what is, in a family or a small community, habit today if we get sick because of minor illnesses. A care provider in such circumstances is considered as a care giver, but usually is not a professional. The beginnings of medicine date in ancient Greece and the Roman Empire, where the personal hygiene, plumbing fixtures and quarantine gained in importance, when also caring for the patient started gaining professional form. Nursing was in the domain of religious and monastic activities, but still there were not necessary professional competences. The first organized systems of home visits began to operate in England in 1816, with the creation of "Committee of Benevolent Ladies" (Committee of Charity Wives), who visited sick children at home (Vuga, 1975). "The Ladies Health Society of Manchester" founded in Manchester in 1862, in order to teach people about a physical, social, moral and religious regime. In 1845, at the Crimean Front, Florence Nightingale cared for the wounded. Florence Nightingale is considered as the initiator of the modern sisterhood. In 1860, she established the first nursing school for civil nurses/sisters in St. Thomas Hospital in London. "District Nursing", as community nursing is called today in England, began to work in Liverpool in 1867 (Vuga, 1975). With the development of medicine, school for "Health Visitors" was established in England in 1892. Those were the first trained community nurses.

In 1914, in Vienna, Angela Boškin from Slovenia graduated as a civil nurse, professionally trained to work on field. 
Sister Boškin was appointed as the first caring field sister in Yugoslavia on 27/01/1919. The scope of her assignments was to protect mothers and children and anti tuberculosis activities. Those were the predecessors of today's community nurses and social workers (Vuga 1975, p. 19).

For the development of the community nursing activities is very important the establishment of the World Health Organization (WHO) in 1948. The WHO in 1958 convened the European Conference of community nurses in Helsinki, where concepts for home care were adopted, still valid today. The WHO defines community nursing as a special form of health care, which includes active health and social care for individuals, families and communities that are due to biological characteristics or certain diseases particularly susceptible to environmental influences.

In the document - Recommendation 24 (Council of Europe), Committee of Ministers of the Council of Europe, are given adopted recommendations, inter alia, the need of integrating the content of palliative care into training programs for health professionals. Palliative care should be an integral part of health care, which has comprehensive and specific programs, which have to be designed interdisciplinary and include experts from various professional levels. The contents are defined in the framework of the National Program of Palliative Care, which defines palliative care principles and objectives of nursing at patients' home, in care institutions, within providers of institutional care, part-time or full time, or in hospice. A group of experts provides multidisciplinary treatment as a team (Železnik, Horvat, Panikvar Žlahtič, Filej \& Vidmar, 2011). In the National Programme of Palliative Care, health care in community nursing has an important place. Community nurses are, in the network of palliative care, listed as members of the basic, as well as specialist palliative team of primary health care (Ministry of Health, 2010, p.14).

\section{Research Problem}

In palliative care, even if we hear about it, and even it is, in some environments, carried out at home, a number of dilemmas can be identified. Problems arise already in the structure of the organizational model, which is supposed to include, in addition to the real, also psychosocial level of care. A series of contradictions were identified when reviewing the issue of the functioning of palliative team at the primary level. Communication dilemmas are caused by ignorance and often fear. Lack of knowledge is recorded in the ways of experiencing death, in the monitoring of the dying patient and family, and too weak awareness of the needs of the dying and their families. As the closest ones are afraid of death in many environments, they are trying to push the dying into institutional environment. However, patients would like to die at home, in an environment that is close to them and calm them down.

Although the National Program of Palliative Care (Ministry of Health of the Republic of Slovenia, 2010) has been written, it still remains at the declarative level. Transfer into practice has not happened yet, especially nothing has happened in the field of competent communication - not only communication with the dying, but also communication with their relatives.

\subsection{Research Model}

As a sample, 181 community nurses working in community activities, representing 22.18 per cent of all employees in community nursing in Slovenia, according to the National Institute of Public Health (2012) were selected. Deliberately were chosen community nurses according to the regional areas and their organizational form of employment. The sample was diverse, encompassing all regional areas of Slovenia and all organizational forms of community nursing (nurses employed in public institutions or employed on the basis of the concession agreement).

\subsection{Research Methods and Techniques}

The choice of methodology was based on problem identification, since we find the populations of community nurses perceive the palliative care process very differently, and with different emotional responses too. We decided to check whether the established model satisfies the needs of the patients and their families. Our main aim was to optimize the model based on our findings, especially in the fields we studied and which play one of the most important roles in the palliative care process - the fields of knowledge, communication, and information.

Data collection method in our study is a survey, which represents one of the fundamental research approaches in social sciences. We surveyed community nurses who are privately employed and those, who are employed in the public institution. As we wished to include the highest number of community care nurses possible, we used our own instrument, a survey questionnaire.

We started collecting data at the end of year 2013. Survey participants were asked to participate both orally and in 
writing, and were ensured anonymity. The survey questionnaire was given to half of the survey participants in person, on a symposium in Laško in September of 2013, and the other half received them by mail.

We transcribed the data collected with the survey questionnaires into a computer database and processed them with the help of a statistical program SPSS. We used quantitative statistic methods - method of analysis, synthesis, and generalization. In the first phase of the analysis we analyzed the statements with the method of descriptive statistics and presented them graphically in the form of descriptive statistics or frequency distributions, with which we interpreted each individual question of the survey. After the Cronbach Alfa reliability test, factor analysis followed. With it, we aimed to find whether the connections between the observed variables can be explained by a lower number of factors. These factors were determined by the principal component analysis. Then, we searched for statistically significant correlations, using Pearson rang correlation coefficient. After finding statistically significant correlations, we further used regression analysis to determine relations between two independent variables and one dependent variable. With regression analysis, we confirmed correlations, meaning that we confirmed the hypothesis. After hypothesis validation, we formed a regression model.

\section{Results}

The study included 180 registered nurses and one graduate nurse. Majority $61.9 \%$ of them are community nurses employed in public institutions, $37.6 \%$ are community nurses with concession, and one respondent did not answer this question.

The aim of this study was to determine the extent to which community nurses believe that patients, their relatives and other important people to a patient are informed about the stage of the disease and about palliative care plan.

Regarding their answers to the question "Are palliative patients, in your field of activity, familiar with the state of the disease?" most of them think $67.4 \%$ that palliative patients are often informed about the state of the disease. At least $10.5 \%$ believe that palliative patients are familiar with the state of the disease. From the above, it can be concluded that the professionals, in most cases, avoid talking with patients about the state of their disease, especially in cases when it comes to advanced, chronic disease, where recovery is no longer possible.

Regarding the answers to the question "Are palliative patients in your field of activity familiar with the plan of palliative care?" majority, i.e. 53.0\% of them felt that palliative patients are rarely informed about the plan of palliative care. Only six (3.3\%) of them believe that palliative patients are never informed about the plan of palliative care. Out of these data it is obvious how difficult it is for the practitioners to talk with the patient about their condition, and the fact that the treatment is concluded, that the cure is no longer possible, further on only mitigation of the disturbing symptoms can be provided.

Regarding the question "Are relatives of the palliative patients and other important people to a patient, in the field you are in charge of, informed about the state of the disease?", majority respondents, $64.1 \%$ of them believe that families are often familiar with the state of the patient's disease. There was no answer "never".

Regarding the question "Are the relatives or important people to a palliative patients, in your field of work, familiar with the plan of palliative care?", majority, $45.9 \%$ of them believe that relatives of palliative patients and other patient's VIPs, are often informed about the palliative care plan. Few of them, 3.3\% stated that relatives were never familiar with the plan. From the above, we can conclude that in most cases, relatives, or other important person to a patient are familiar with the plan of palliative care. It means that the professionals easier speak with relatives than with patients.

In opinion of $65.7 \%$ respondents, patient's relatives are often included into patient's care in the context of palliative care. There was no answer "never". The smallest number of the respondents $6.1 \%$ answered that patient's relatives are rarely included into the care of the patients in the context of palliative care.

To palliative patients of greatest importance are interpersonal communication, frequency and mode of communication between members of the palliative team. Therefore, we wanted to get answers about these issues.

According to the 179 community nurses, all members of the palliative team have good interpersonal communication, since 58.0\% answered the question affirmatively; two of them did not know the answer to this issue. This can be understood as the fact that the principles and functioning, and the importance of palliative care are not yet widely known among the palliative care professional providers. Even communication, as the main element of teamwork in the process of palliative care, in two cases was completely unknown, what means that there was no teamwork in dealing with the patient in the process of palliative care.

Out of 174 respondents, $81.8 \%$ give negative answer to the question "Do you keep a regular meeting with the members of the palliative team at the primary level about individual cases in your region?" Seven of them (3.9\%), do not know the answer. From the above, we can conclude that teamwork in the process of palliative care is rarely carried out in 
Slovenia. Finding that some of them do not even know whether their team hold meetings on this topic is concerning. It opens a dilemma - is it because of ignorance or lack of interest?

Following question was about the extent to which community nurses build their knowledge in the field of palliative care throughout permanent education and how their upgraded knowledge affects their work in the field of palliative care.

According to the respondents, there are $45.3 \%$ of those who feel they have enough knowledge to provide quality care for palliative patients. $34.8 \%$ of respondents state that their knowledge is insufficient. Having a sense of lack of competence, this feeling seems logical. But this seems non-professional, to provide professional care for patients being aware of the lack of knowledge. Non-professional attitude affects the care of patients and, on the other hand, the selfimage of a professional provider. At this level, regulations should be provided for the continuous education of nurses. Their knowledge are not able to define $19.9 \%$ community nurses.

Communication and knowledge were chosen as the components/building blocks of the quality of life of patients and their relatives, because a competent, sensible communication affects not only familiarity with the state of a disease and palliative care plan, but also the motivation to deal with the disease.

Table 1: Correlations between familiarity, communication, community nurses activities, region and knowledge

\begin{tabular}{|c|c|c|c|c|c|c|}
\hline & & You function as & $\begin{array}{l}\text { Regional field of } \\
\text { activity (more } \\
\text { answers possible) }\end{array}$ & Familiarity & $\begin{array}{l}\text { Do you think you have } \\
\text { enough knowledge to } \\
\text { offer quality care to the } \\
\text { palliative patients? }\end{array}$ & Communication \\
\hline Functioning as & $\begin{array}{l}\text { Pearson Corr. } \\
\text { Sig. (2-tailed) } \\
\text { N }\end{array}$ & $\begin{array}{c}1 \\
180 \\
\end{array}$ & & & & \\
\hline $\begin{array}{l}\text { Regional field of activity (more } \\
\text { answers possible) }\end{array}$ & $\begin{array}{l}\text { Pearson Corr. } \\
\text { Sig. (2-tailed) } \\
\text { N }\end{array}$ & $\begin{array}{c}0,197 \\
0,008 \\
180\end{array}$ & $\begin{array}{c}1 \\
181\end{array}$ & & & \\
\hline Familiarity & $\begin{array}{l}\text { Pearson Corr. } \\
\text { Sig. (2-tailed) } \\
\text { N }\end{array}$ & $\begin{array}{c}0,064 \\
0,393 \\
180\end{array}$ & $\begin{array}{c}-0,144 \\
0,052 \\
181\end{array}$ & $\begin{array}{c}1 \\
181\end{array}$ & & \\
\hline $\begin{array}{l}\text { Do you think you have enough } \\
\text { knowledge to offer quality care } \\
\text { to palliative patients? }\end{array}$ & $\begin{array}{l}\text { Pearson Corr. } \\
\text { Sig. (2-tailed) } \\
\text { N }\end{array}$ & $\begin{array}{c}0,084 \\
0,263 \\
180\end{array}$ & $\begin{array}{c}-0,152 \\
0,041 \\
181\end{array}$ & $\begin{array}{c}0,188 \\
0,011 \\
181\end{array}$ & $\begin{array}{c}1 \\
181\end{array}$ & \\
\hline Communication & $\begin{array}{l}\text { Pearson Corr. } \\
\text { Sig. (2-tailed) } \\
\mathrm{N}\end{array}$ & $\begin{array}{c}0,135 \\
0,078 \\
171\end{array}$ & $\begin{array}{c}-0,008 \\
0,92 \\
172\end{array}$ & $\begin{array}{c}0,261 \\
0,001 \\
172\end{array}$ & $\begin{array}{c}0,02 \\
0,795 \\
172\end{array}$ & $\begin{array}{c}1 \\
172\end{array}$ \\
\hline
\end{tabular}

Weak relation is present between the regions of the participating nurses, as well as between combined indicators, named »familiarity « and opinion, "Do you think you have enough knowledge to offer quality care to palliative patients?". The relationship is also evident between the integrated indicators, called "knowledge and communication", as the Pearson correlation coefficient is 0.261 .

In the study, following hypothesis was set:

$\mathrm{H}$ : Community nurses claim that communication between the members of the palliative team, and their knowledge about quality care for palliative patients, have statistically significant impact on patient and family's familiarity with a disease and palliative care plan.

\begin{tabular}{|c|c|c|c|c|}
\hline & & Familiarity & Communica & $\begin{array}{l}\text { Do you think you have enough knowledge } \\
\text { to offer quality care to the palliative } \\
\text { patients? }\end{array}$ \\
\hline Familiarity & $\begin{array}{l}\text { Pearson Corr. } \\
\text { Sig. (2-tailed) } \\
\mathrm{N}\end{array}$ & $\begin{array}{c}1 \\
181\end{array}$ & & \\
\hline Communication & $\begin{array}{l}\text { Pearson Corr. } \\
\text { Sig. (2-tailed) } \\
\text { N }\end{array}$ & $\begin{array}{c}0,261 \\
0,001 \\
172 \\
\end{array}$ & $\begin{array}{c}1 \\
172 \\
\end{array}$ & \\
\hline $\begin{array}{l}\text { Do you think you have enough } \\
\text { knowledge to offer quality care to the } \\
\text { palliative patients? }\end{array}$ & $\begin{array}{l}\text { Pearson Corr. } \\
\text { Sig. (2-tailed) } \\
\text { N }\end{array}$ & $\begin{array}{c}0,188 \\
0,011 \\
181 \\
\end{array}$ & $\begin{array}{c}0,02 \\
0,795 \\
172\end{array}$ & $\begin{array}{c}1 \\
181 \\
\end{array}$ \\
\hline
\end{tabular}


Pearson's correlation indicates a weak correlation $(0.261)$ between the two variables sfamiliarity of patient and family with the state of disease and palliative care plan« and »communication between members of the palliative team«. A weak correlation (0.188) can also be seen between the two variables »familiarity and opinion about »community nurses knowledge to offer quality care to palliative patients«.

The regression model between familiarity, communication and knowledge

\begin{tabular}{|c|c|c|c|c|}
\hline Model & $\mathbf{R}$ & $\mathbf{R}$ Square & Adjusted R Square & Std. Error of the Estimate \\
\hline 1 & $0,340^{\mathrm{a}}$ & 0,116 & 0,105 & 0,42364 \\
\hline
\end{tabular}

Note: a. Predictors: (Constant), communication, »Do you think you have enough knowledge to offer quality care to palliative patients«

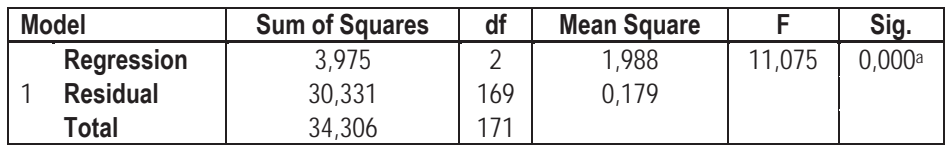

Note: a. Predictors: (Constant), communication, Do you think you have sufficient knowledge in order to offer quality care to palliative patients?

b. Dependent Variable: familiarity

\begin{tabular}{|l|l|c|c|c|c|c|}
\hline \multirow{2}{*}{ Model } & \multicolumn{2}{|c|}{$\begin{array}{c}\text { Unstandardized } \\
\text { Coefficients }\end{array}$} & $\begin{array}{c}\text { Standardized } \\
\text { Coefficients }\end{array}$ & \multirow{2}{*}{$\mathbf{t}$} & Sig. \\
\cline { 2 - 4 } & $\mathbf{B}$ & Std. Error & Beta & & \\
\hline 1 & 1,37 & 0,17 & & 8,069 & 0 \\
\hline $\begin{array}{l}\text { (Constant) } \\
\text { Do you think you have enough knowledge to offer }\end{array}$ & 0,128 & 0,042 & 0,219 & 3,021 & 0,003 \\
\hline Communication & 0,327 & 0,092 & 0,257 & 3,547 & 0,001 \\
\hline
\end{tabular}

Note: a. Dependent Variable: familiarity

The regression model shows a statistically significant relationship between »communication between the palliative care team«, opinion »Do you have enough knowledge to offer quality care to palliative patients?« and the dependent variable »familiarity«. Thus, hypothesis is confirmed.

It means, where there is a good communication between members of the palliative team, there is also appropriate familiarity of patients and family with the state of disease and palliative care plan. Those community nurses who feel that they have enough professional and communication knowledge to offer quality care to palliative patients, better inform patients and their relatives about the disease and palliative care plan.

\section{Model of Independent Variables and their Impact on the Dependent Variable »Familiarity»}

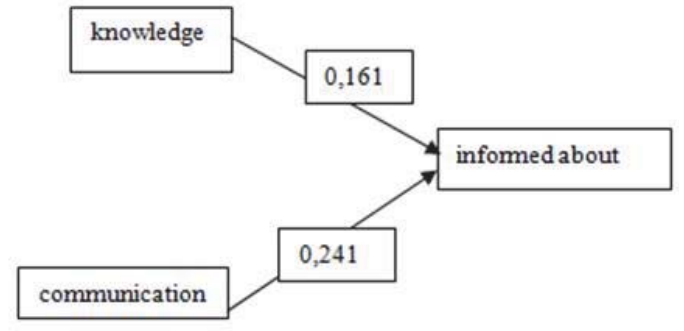

Source: own

\section{Conclusion}

For the quality of life in the palliative care process is crucial to help patients satisfy their physical, mental, social and spiritual needs.

This study shows that, according to community nurses' point of view, communication is a critical component of palliative care. Each component of "good death" depends primarily on the communication of all actors involved in the 
process. It greatly affects the quality of care and the quality of life of the dying and their family members. Apart from supporting the patient and family, communication helps build trust and is the foundation for overcoming obstacles and distractions, relieving the symptoms of advanced, incurable disease. Or, to cite the words of Dame Cicely Saunders: "Do everything you can, not only for a peaceful death, but for life until death." This goal can be achieved throughout communication which enables humans to have a genuine human relationship even in times of death or as Trstenjak says: "Allow a man to be a man."

\section{References}

Arnaert, A., Van Den Heuvel, B., \& Windey, T. (2005). Health and Social Care Policy for the Elderly in Belgium. Geriatric Nursing, 26(6), 366-371.

Brumley, R., Enguidanos, S., Jamison, P., Seitz, R., Morgenstern, N., Saito, S., Mcllwane, J., Hillary, K., \& Gonzales, J. (2007). Increased satisfaction with care and lower costs: results of a randomized trial of in-home palliative care. Journal of the American Geriatrics Society, 55(7), 993-1000.

Buckman, R. (1984). Breaking bad news: why is it still so difficult? British Medical Journal (BMJ), 288,1597-1599.

Burge, F., Lawson, B., \& Johnston, G. (2003). Trends in the place of death of cancer patients, 1992-1997. Canadian Medical Association Journal, (CMAJ) 168(3), 265-270.

Chang, E., Bidewell, J., Hancock, K., Johnson, A., \& Esterbrook, S. (2012). Community palliative care nurse experiences and perceptions of follow-up bereavement support visits to carers. International Journal of Nursing Practice, 18(4), 332-339.

Corner, J. (2003). The multidisciplinary team - fact or fiction? European Journal of Palliative Care, 10(2), 10-13.

Department of Health. (2008). End of Life Care Strategy - promoting high quality care for all adults at the end of life. London. Available at: https://www.gov.uk/government/publications/end-of-life-care-strategy-promoting-high-quality-care-for-adults-at-the-end-oftheir-life. (15.12.2014).

El-Jawahri, A., Greer, J., \& Temel, J. (2011). Does palliative care improve outcomes for patients with incurable illness? A review of the evidence. Journal of Supportive Oncology, 9(3), 87-94.

Field, D., Reid, D., Payne, S., \& Relf, M. (2006). Adult bereavement in five English hospices: participants, organisations and prebereavement support. International journal of palliative nursing, 12(7), 320-327.

Gholve, P., Kosygan, K., Sturdee, S.W., \& Faraj, A. (2005). Multidisciplinary integrated care pathway for fractured neck of femur: A prospective trial with improved outcome. Injury, 36(1), 93-98.

Giddens, A. (1984). The Constitution of Society. Outline of the Theory of Structuration. United States of America: University of California Press.

Giddens, A. (1989). New rules of sociology method. Ljubljana: Studia humanitatis.

Gomes, B., Calanzani, N., \& Higginson, I. (2012). Reversal of the British trends in place of death: Time series analysis 2004-2010. Palliative Medicine, 26(2), 102-107.

Gómez-Batiste, X., Martinez-Munoz, M., Blay, C., Espinosa, J., Contel, J., \& Ledesma, A. (2012). Identifying needs and improving palliative care of chronically ill patients: a community oriented, population-based, public health approach. Palliative Care, 6, 371378.

Heaven, C., \& Maguire, P. (1996). Training hospice nurses to elicit patient concerns. Journal of Advanced Nursing, 23(2), 280-286.

Higginson, I., Astin, P., \& Dolan, S. (1998). Where do cancer patients die? Ten years trends in the place of death of cancer patients in England. Palliative Medicine, 12(5), 353-363.

National Institute of Public Health. 2012. Community nursing care employees of Slovenia, January 2012. Available at: http://www.ivz.si/podatkovne_zbirke?pi=5\&_5_Filename=attName.png\&5Mediald=6478\&_5_AutoResize=false\&pl=46-5.3. (5.8.2014).

Joly, F., Heron, J., Kalusinski, L., Henry - Amar, M., \& Allouache, N. (2002). Quality of life in long-term survivors of testicular cancer: a population-based case-control study. Journal of Clinical Onkology, 20, 73-80.

Keller, M., Heinrich, G., Sellschopp, A., \& Beutel, M. (1996). Between distress and support; spouses of cancer patients. In: Badier, I., Cooper, C.L., Kaplan De-Nour, A., eds. Cancer and the family. Chiester: John Wiley \& Sons Ltd, 187-223.

Klevišar, M. 1996. Accompanying the dying. Ljubljana: Family.

Klevišar M. 1997. Death as a reconciliatory end of life. In: Hojnik Zupanc Ida. Let's add life to the years. Ljubljana: Gerontological association of Slovenia, 149-157.

Landi, F., Onder, G., Russo, A., Tabaccanti, S., Rollo, R., Federici, S., Tua, E., Cesari, M., \& Bernabei, R. (2001). A new model of integrated home care for the elderly: impact on hospital use. Journal of Clinical Epidemiology, 54(9), 968-970.

Lunder, U., \& Kersnik, J. (2003). Communicating bad news. Ljubljana: Medical Views Journal, 42(1), 73-79.

Marušič, A., \& Roškar S. (2003). Slovenia with or without suicide. Ljubljana: National publisher of Slovenia, DZS.

Ministry of Health of the Republic of Slovenia. 2010. National program of palliative care. Ljubljana, March of 2010.

Muray, C., \& Lopez, A. (1997). Alternative projections of mortality and disability by cause 1990-2020: Global Burden of Disease Study. Lancet, 349(9064), 1498-504.

Nies, H., \& Berman, P. (2004). Integrating services for Older people: A resource book for managers. Dublin: European Health Management Association (EHMA). 
Ovsenik, M. (2014). Competence - response to the crisis. In: Železnik, Danica, eds. Importance of competent treatment of health care and social care users in the time of crisis. 4th. Scientific conference with international participation in the field of healthcare and social sciences. Slovenj Gradec: University college of health sciences, 9. 9. 2014, 33-40.

Ovsenik, M., \& Ambrož, M. (2010). Integrity and insignificance of organization. Ljubljana: Institute of management.

Parker, S., Clayton, J., Hancock, K., Walder, S., Butow, P., Carrick, S., Currow, D., Ghersi, D., Glare, P., Hagerty, R., \& Tattersall, M. (2007). A systematic review of prognostic/end-of-life communication with adults in the advanced stages of a life-limiting illness: patient/caregiver preferences for the content, style, and timing of information. Journal of Pain and Symptom Management, 34(1), $81-93$.

Peternel, A. (2008). Palliative care as a building block of quality patient care. In: Palliative care nurse by the side of a dying patient. Collection of lectures. 2nd Experts meeting ZZPMS, Sp. Duplek, 15.4.2008, 15-19.

Reinke, L., Slatore, C., Uman, J., Udris, E., Moss, B., Engelberg, R., \& Au, D. (2011). Patient-clinician communication about end-of-life care topics: is anyone talking to patients with chronic obstructive pulmonary disease? Journal of Palliative Medicine, 14(8), 923928.

Shanawani, H., Wenrich, M., Tonelli, M., \& Curtis, R. (2008). Meeting physicians' responsibilities in providing end-of-life care. Chest Journal, 133(3), 775-786.

Schwenk, T. (2002). Diagnosis of late life depression: the view from primary care. Biological Psychiatry, 52(3),157-163.

Slak, J. (2011). Nursing care of the patient at the end of life. In: Žontar, T., Kvas, A. eds. Palliative care of the cardiovascular patient. Collection of reviewed papers. XXVIX. Experts meeting of the section of nursing staff and healthcare technicians in cardiology and angiology. Šmarješke Toplice, 11th of november 2011. Ljubljana: Nurses and Midwives Association of Slovenia, 21-29.

Statistical Office of the Republic of Slovenia. 2012. Statistical annual 2012. Available at: http://stat.si/letopis/ (20.08.2013).

Qaseem, A., Snow, V., Shekelle, P., Casey, D., Cross, T., \& Owens, D. (2008). Evidence-based interventions to improve the palliative care of pain, dyspnea, and depression at the end of life: a clinical practice guideline from the American College of Physicians. Annals of Internal Medicine, 148(2), 141-146.

Quill, T. (2000). Initiating end-of-life discussions with seriously ill patients: addressing the "elephant in the room." The Journal of the American Medical Association (JAMA), 284(19), 2502-2507.

Volkers, A., Nuyen, J., Verhaak, P., \& Schellevis, F. (2004). The problem of diagnosing major depression in elderly primary care patients. Journal of Affective Disorders, 82(2), 259-263.

Vuga, S. (1975). Organization of community nursing care service. Ljubljana: Slovenian nursing review, 9(1), 18-22.

Weil, S. (1985). Trepidation and obedience. Newspaper for thinking, art, cultural, and religious questions. Ljubljana: Association of newspaper publishers 2000.

Wilkinson, S. (1991). Factors which influence how nurses communicate with cancer patients. Journal of Advanced Nursing, 16, 677-688.

World Health Organisation. (2004). Better Palliative Care for Older People. Available at: http://www.palliatief.nl/Portals/31/publicaties/ betterpcolderpeople.pdf (18.7.2014).

Železnik, D., Horvat, M., Panikvar Žlahtič, K., Filej, B., \& Vidmar I. (2011). Healthcare activities in palliative care. Ljubljana: Nurses and Midwives Association of Slovenia. 